\title{
POLAR FIRN DENSIFICATION AND GRAIN GROWTH*
}

\author{
by
}

\author{
Richard B. Alley
}

(Institute of Polar Studies and Department of Geology and Mineralogy, Ohio State University, Columbus, Ohio 43210 , U.S.A.)

\section{John F. Bolzan}

(Institute of Polar Studies, Ohio State University, Columbus, Ohio 43210, U.S.A.)

\section{and Ian M. Whillans}

(Institute of Polar Studies and Department of Geology and Mineralogy, Ohio State University, Columbus, Ohio 43210 , U.S.A.)

\section{ABSTRACT}

A $50 \mathrm{~m}$ firn core from Dome C, East Antarctica, was found to consist of coarse firn, which comprised 90 to $95 \%$ of the core, and fine firn. Coarse firn was characterized by 1 arge crystals with a vertical shape orientation near the surface, connected to nearest neighbors by relatively large necks in a structure different from closest packing. Fine firn was of higher density and consisted of smaller, more spherical crystals connected by relatively narrow necks in a more nearly closest-packed configuration.

Higher surface free energy in fine firn causes crystals and necks to grow more rapidly than in coarse firn. However, we find that coarse firn densifies more rapidly with time, contrary to the predictions of unconfined sintering models. Load-driven densification due to a power-law creep mechanism is found to account for the larger coarse-firn densification rate. However, if the exponent in the power law exceeds one, then densification rates are predicted to increase with depth due to increasing load, contrary to observed behavior. We speculate that different mechanisms may control the densification process in fine and coarse firn.

\section{INTRODUCTION}

Snow deposited on polar ice sheets is transformed to firn and then to ice through processes which involve both densification and recrystallization. Densification is achieved through the elimination of pore space, while recrystallization involves the change of crystal shape and size, and the production and growth of crystal bonds.

In near-surface regions, diurnal and seasonal variations produce layers with different properties. Since pore spaces in firn are in contact with the atmosphere, no process in firn is totally free of atmospheric influence. However, the annual temperature wave is mostly damped out by $10 \mathrm{~m}$ depth, and the effects of shorter-term temperature variations and other surface processes are significant to only a few meters depth. As a first approxination, distinct 7 ayers are assumed to develop only in the upper few meters. As these layers are buried, they enter a relatively isothermal region extending from about $10 \mathrm{~m}$ depth to the firn-ice transition. The rate at which densification and recrystallization occur in this region is ultimately related to the mean annual temperature and accumulation rate, and to the structure of the firn entering the region.

This paper reports the results of studies on the firn structure of a $50 \mathrm{~m}$ core taken froin Dome $C$, East Antarctica, during the $1973-79$ austral suminer. Dome $C$ camp is located on an ice divide at $74^{\circ} 30^{\prime} \mathrm{S}, 123^{\circ} 10^{\prime} \mathrm{E}$, elevation $3240 \mathrm{~m}$. Measurements by Bolzan (unpub1ished) during the 1978-79 and 1979-80 austral summers indicate that the $10 \mathrm{~m}$ temperature is about $-54.3^{\circ} \mathrm{C}$. The mean annual accumulation rate is $34 \mathrm{~kg} \mathrm{~m}^{-2} \mathrm{a}^{-1}$ (Palais 1980) and the firn-ice transition is at about $100 \mathrm{~m}$ depth (Raynaud and others 1979).

The $75 \mathrm{~mm}$ diameter core was drilled by personnel from the Polar Ice Coring office in Lincoln, Nebraska, USA, and was shipped to Columbus where it was studied during the fall and winter of 1979-80.

\section{CORE DESCRIPTION}

$V$ isual inspection of the core, as well as exainination in transmitted 1 ight, reveais distinct layering. Individual layers range fron one to several tens of millimeters in thickness. The core is mainly conposed of coarse-grained firn with high light transmissivity, but 5 to $10 \%$ of the core consists of thin, finegrained layers of low transinissivity. Contacts between layers are abrupt. Although more distinct at the surface, layers are still well defined at $50 \mathrm{~m}$. At no point is there any clear indication of regular spacing corresponding to annual layering, or any other regularity. There are also small variations in transmissivity and grain-size within the coarse firn, but these variations were not as pronounced as those between coarse and fine firn, and were not closely investigated.

${ }^{\star}$ Ohio State University. Institute of Polar Studies. Contribution No.415. 
RESULTS

\section{Density measurements}

The densities of $1 \mathrm{~m}$ long core sections were measured, as well as the densities of superjacent fine and coarse firn layers. The density variation with depth of the $1 \mathrm{~m}$ long firn sections defines an "average" density profile and is given by

$$
\rho(z)=0.922-0.564 \exp (-0.0165 \mathrm{z}) \mathrm{Mg} \mathrm{m}^{-3} \text {; }
$$

for fine firn the density varies with depth according to

$$
\rho(z)=0.922-0.491 \exp (-0.0133 z) \mathrm{Mg} \mathrm{m}^{-3} \text {, }
$$

while for coarse firn

$$
\rho(z)=0.922-0.573 \exp (-0.0163 z) \mathrm{Mg} \mathrm{m}^{-3} \text {. }
$$

where $z$ is the depth in meters.

The correlation coefficients for the empirical fits to the density data given by Equations (1), (2), and $(3)$ are $0.995,0.989$, and 0.996 respectively. The data for fine and coarse firn, along with the analytical fits, are plotted in Figure 1. Firn ages were

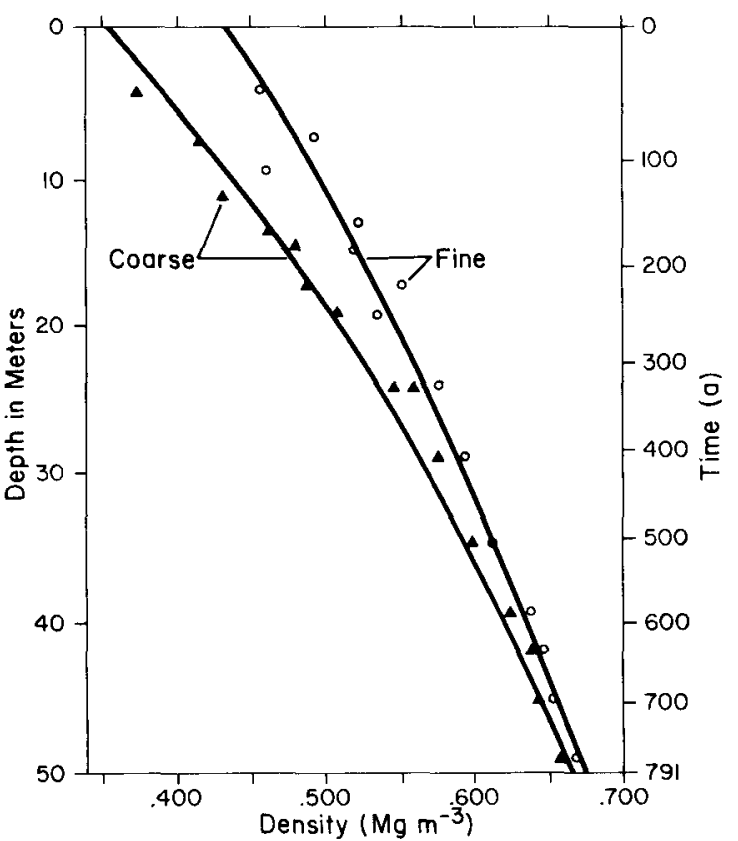

Fig.1. Density as a function of depth for coarsegrained and fine-grained firn. Solid lines are empirical fits to the data described in the text.

calculated using the average density profile. From Figure 1 it is apparent that (1) coarse firn is initially less dense than fine firn, (2) coarse firn densifies more rapidly than fine firn of equal age, causing the difference in density between coarse and fine firn at a given age to decrease with time, and it can be shown that (3) coarse firn densifies more rapidly than fine firn of equal density.

\section{Crystal-size measurements}

Crystal cross-sectional areas for fine and coarse firn are plotted in Figure 2. For details of the measurement procedure see Alley (1980).

Gow (1969) and Stephenson (1957) observed that crystal area increases linearly with time in the isotherma? region; that is

$$
A=A_{0}+K t
$$

where $A$ is the mean cross-sectional area at time $t$, $A_{0}$ is the extrapolated mean cross-sectional area at

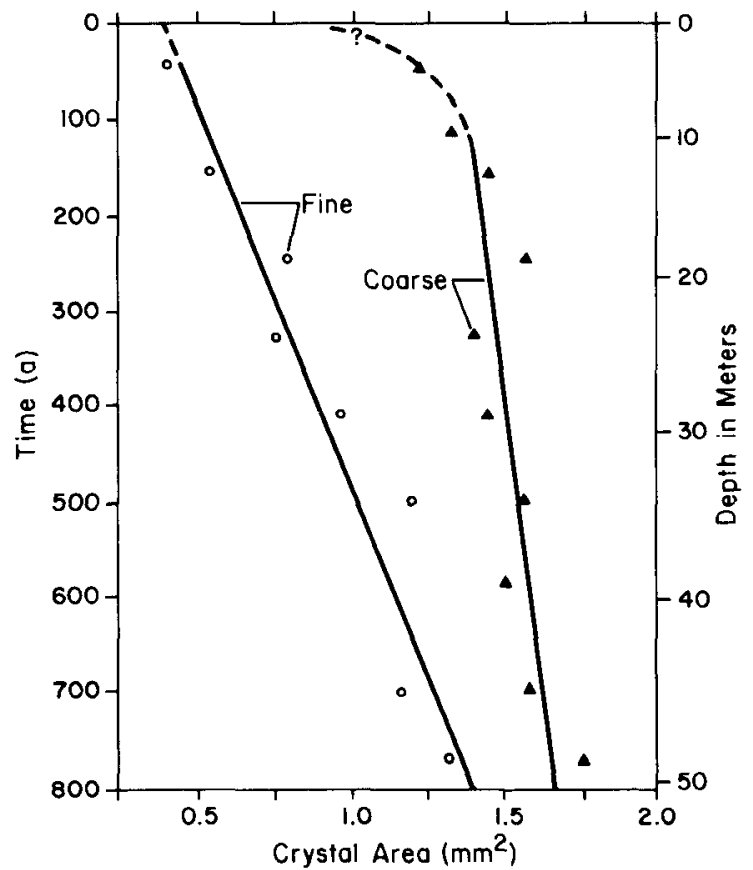

Fig.2. Crystal cross-sectional area as a function of time for coarse-grained and fine-grained firn.

time zero, and $K$ is the crystal-growth rate, usually expressed in $\mathrm{mm}^{2} \mathrm{a}^{-1}$. From Figure 2 we see that the Dome $C$ data are in good agreement with this relation. A linear least-squares fit gives a growth rate of about $4.2 \times 10^{-4} \mathrm{~mm}^{2} \mathrm{a}^{-1}$ for coarse firn and $1.2 \times 10^{-3} \mathrm{~mm}^{2} \mathrm{a}^{-1}$ for fine firn, a growth rate nearly three times as large.

Gow (1969) has found that the crystal-growth rate can be related to the mean annual temperature by

$$
K=K_{0} \exp (-E / R T)
$$

where $K_{0}$ is a constant, $R$ is the gas constant, $T$ is the mean annual temperature in kelvins, and $E$ is the activation energy for the crystal-growth process. Data reported in Gow (1969) on growth rates and ternperatures for five sites in Greenland and Antarctica fix $K_{0}$ at $6.75 \times 10^{7} \mathrm{~mm}^{2} \mathrm{a}^{-1}$ and the activation energy at $47.0 \times 10^{3} \mathrm{~J} \mathrm{~mol}^{-1}$. For an average firn temperature of $-54.3^{\circ} \mathrm{C}$, Equation (5) gives a growth rate of $4.2 \times 10^{-4} \mathrm{~mm}^{2} \mathrm{a}^{-1}$, in good agreement with the value obtained for coarse firn in this study.

The crystals studied by Gow (1969) were taken without regard to stratigraphy or structure, and so reflect the average firn properties at a particular site. At Dome $C$, the average firn properties are very nearly those of coarse firn, which comprises 90 to $95 \%$ of the firn core. We see that the crystal-growth process for firn at widely scattered polar sites is typical of coarse firn at Dome $C$, even though the typical crystal cross-sectional area varied widely from site to site in Gow's study. At South Pole, for example, crystal sizes measured by Gow near the surface are about the same as those of near-surface fine-firn crystals at Dome $C$. However, fine-firn Dome C crystals proceed to grow twice as rapidly, and do so in firn more than $3^{\circ} \mathrm{C}$ colder.

Sphericity measurements

The sphericity of a crystal in thin section is the diameter of the largest inscribed circle divided by the diameter of the smallest circumscribed circle. Regular polyhedra with many faces have relatively large sphericities, while very elongate or irregular crystals have low sphericities. Figure 3 shows examples of sphericity for some typical crystal shapes.

Average sphericities were measured for each 


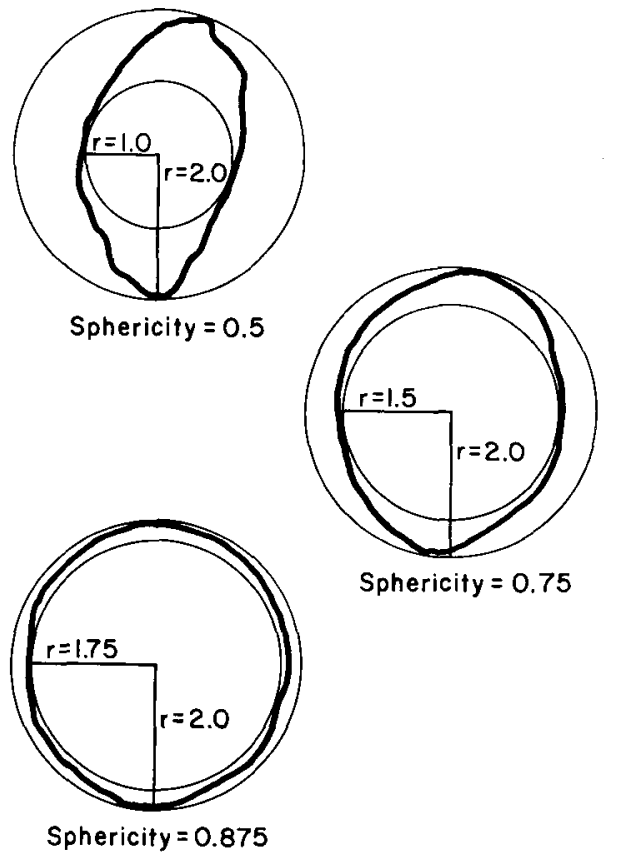

Fig.3. Sphericities of some typical grain shapes.

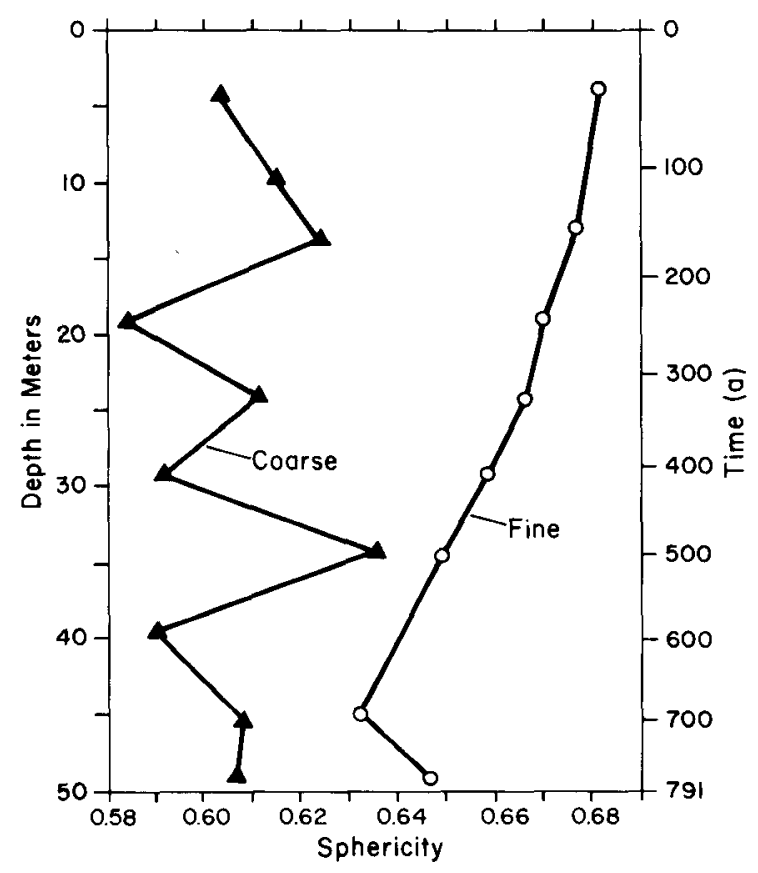

Fig.4. Sphericity as a function of depth for coarsegrained and fine-grained firn.

sample (Alley 1980) and the variation of sphericity with depth for fine and coarse firn is plotted in Figure 4. For fine-grained firn, sphericity decreases steadily with depth to $45 \mathrm{~m}$; then it appears to increase. No such regular behavior is seen for coarsegrained firn. However, we see that crystals in coarse firn tend to be less spherical than crystals in fine firn at the same depth. Possibly the large scatter in the coarse-firn data is due to the inclusion of different types of firn under the label "coarse". It is possible that careful study might allow the distinction of different types of coarse firn at depth, based on sphericity, grain size, and other characteristics. Such a distinction, however, was beyond the scope of the present study.

\section{Surface area measurements}

Based on probability theory, Smith and Guttinan (1953) developed a method to estimate specific areas of crystal boundary (here $S_{c}$ is the total ice-ice interface area per unit volume) and internal free surface (here $S_{f}$ is the total ice-air interface area per unit volume). For a random surface in any threedimensional system:

$$
S=2 \mathrm{~N} / \mathrm{L},
$$

where $S$ is the specific area in $\mathrm{m}^{2} \mathrm{~m}^{-3}$ leither $S_{C}$ or $\left.S_{f}\right), L$ is the total length of line drawn with arbitrary spacing on the surface in $\mathrm{m}$, and $\mathrm{N}$ is the number of intersections between the lines and either free surfaces or crystal boundaries seen on the plane of the section. Details and results of specific area measurements are published in Alley $(1980)$. Some values are given in Table $I$.

The ratio of the specific area of crystal boundary to total specific surface area for a sample, $B=S_{C} /\left(S_{C}+S_{f}\right)$, is also the ratio of crystal-bond area to total crystal-surface area for the average crystal in that sample. From Table I, we see that in general $B$ increases with density. However, even though the density of fine firn is larger than that of coarse, both have similar $\beta$ values. Crystal-bond characteristics

The crystal bond is that surface along which two crystals make contact. The radius $r$ of the average bond in each sample was determined using the method of Fullman (1953) and Kry (1975). The radius $R$ of the average crystal in each sample was calculated from measured crystal cross-sectional areas by assuming that crystals were spherical. Values of $r, R$, and $r / R$ are listed in Table I. The ratio $r / R$ is a measure of the relative size of bond and crystal. From Table I we conclude that bonds in coarse firn are larger relative to their average crystal size and that bond radius and the relative bond size increase more rapidly with time for fine firn.

Since crystal bonds are larger in coarse firn than in fine, but the ratio of crystal bond to total surface area $B$ is nearly the same, it follows that an average crystal in fine firn participates in more bonds than a crystal in coarse firn. Again assuming spherical crystals, the total surface area per crystal $A_{t}$ can be calculated from measured crosssectional areas. The product $\beta \times A_{t}$ is the average area per crystal involved in bonding. For bonds of circular cross-section, the number of bonds per crystal is then

$$
N_{b}=\beta A_{t} / \pi r^{2}=4 \beta(R / r)^{2} .
$$

Values of $N_{b}$ are listed in Table $I$. The number of assumptions involved in this calculation is considerable, so that the results obtained must be treated as rough approximations (Kry 1975). We tentatively conclude that crystals in fine firn are bonded to more nearest neighbors than crystals in coarse firn. The number of bonds per crystal may increase somewhat with depth for coarse firn, but any trends are poorly defined.

\section{DISCUSSION}

Gow $(1969,1975)$ treated densification of firn as being analogous to the unconfined sintering of ceramics, a process in which a ceramic powder heated near its melting point densifies in the absence of a confining stress. The driving force for unconfined sintering is provided by the large free energy of crystal surfaces relative to the free energy of the lattice structure that forms the interior of the crystal (surface free energy). This driving force varies inversely with the radius of curvature of grain surfaces, so that an increase in the radius of curvature of nearly spherical grains from 1 to $10 \mu \mathrm{m}$ decreases the rate of sintering by a factor of 10 
TABLE I. VARIATION OF FINE AND COARSE FIRN PARAMETERS WITH DEPTH

\begin{tabular}{|c|c|c|c|c|c|c|c|c|}
\hline $\begin{array}{l}\text { Depth } \\
(\mathrm{m})\end{array}$ & Firn type & $\left(m^{2} m^{S} m^{-3}\right)$ & $\left(m^{2}{ }_{m_{f}}^{S^{-3}}\right)$ & $B$ & $\stackrel{r}{(m m)}$ & $\stackrel{R}{R}$ & $r / R$ & $\mathrm{~N}_{\mathrm{b}}$ \\
\hline 4.07 & fine & 594.8 & 4185.7 & 0.124 & 0.112 & 0.358 & 0.313 & 6.6 \\
\hline 19.25 & fine & 955.6 & 1978.6 & 0.326 & 0.214 & 0.552 & 0.388 & 6.8 \\
\hline 29.03 & fine & 1037.6 & 1715.0 & 0.377 & 0.222 & 0.552 & 0.401 & 7.9 \\
\hline 49.11 & fine & 958.8 & 1306.5 & 0.423 & 0.378 & 0.646 & 0.585 & 5.2 \\
\hline 4.16 & coarse & 286.6 & 2226.2 & 0.114 & 0.267 & 0.623 & 0.429 & 3.0 \\
\hline 19.29 & coarse & 452.0 & 1860.5 & 0.195 & 0.336 & 0.706 & 0.476 & 4.1 \\
\hline 29.05 & coarse & 437.8 & 1463.1 & 0.230 & 0.400 & 0.677 & 0.591 & 3.4 \\
\hline 49.07 & coarse & 1030.8 & 1044.7 & 0.497 & 0.497 & 0.746 & 0.666 & 3.8 \\
\hline
\end{tabular}

(Budworth 1970). Based on this argument, one would expect that fine-grained firn would densify more rapidly than coarse-grained firn of equal density.

A possible explanation for the observed densification behavior may be the way in which fine and coarse firn structures respond to load. Crystals in coarse firn are joined by relatively wide necks to a few (3 or 4) neighbors. This configuration is probably the result of extensive diagenesis due to the large temperature gradient in the near-surface region. crystals in coarse firn exhibit a strong vertical shape orientation near the surface (Alley 1980), perhaps as a result of strong vertical vapor and heat transport. This structure is far from closest packing and might be expected to undergo significant particle rearrangement under an applied load.

crystals in fine firn tend to be more spherical and are joined by relatively narrow necks to many ( 6 or 7 ) neighbors. This configuration may result from wind-packing, followed by 7 imited diagenesis due to the large temperature gradient in the nearsurface zone. Unlike coarse firn, fine-firn crystals exhibit no shape orientation close to the surface (Alley 1980). This structure is more nearly closest packed and might be expected to be more stable under an applied load, as particles are less able to undergo extensive rearrangement.

Theoretically, several distinct mechanisms may operate simultaneously during the densification process. These include diffusion mechanisms such as volume, surface, and grain-boundary diffusion, mechanisins involving the mechanical deformation of particles such as creep and plastic flow, the transport of mass by evaporation and condensation, and particle rearrangement as grains slide past each other in response to an applied stress. The overall densification rate is then a suin of rates due to the various operative mechanisms, with different mechanisins possibly being dominant at different stages of the sintering process. We may ask then, what is the dominant mechanisin for the densification of fine and coarse firn and is the same mechanisin dominant for both fine and coarse firn?

Coble (1970) has derived expressions for the densification rates due to lattice diffusion and grain-boundary diffusion mechanisms. He explicitly incorporated the effect of load and assumed that closed spherical pores are distributed uniformly throughout the material and that the diffusional flux is spherically symmetric. For the grain-boundary diffusion mechanism, he also assumes that three grain boundaries pass through each pore (see Wilkinson and Ashby 1975). We have used these models to calculate densification rates for fine and coarse firn with one modification. Since the overburden is supported only at crystal-crystal contacts, we have taken the

applied load to be the effective stress, $\mathrm{P}_{\mathrm{b}}$, acting across a crystal bond or neck:

$$
P_{b}=P_{a}\left(S_{C}+S_{f}\right) / S_{C},
$$

where $\mathrm{P}_{\mathrm{a}}$ is the overburden.

The results of our calculations indicate that both diffusion-controlled models predict that fine firn should densify more rapidly than coarse firn, in agreement with earlier qualitative considerations, but contrary to observed behavior. We conclude, at least within the context of Coble's models, that diffusion-controlled mechanisms are not dominant for both fine and coarse firn.

wilkinson and Ashby have considered the pressure sintering process when densification is controlled by mechanical creep. They assume that the distribution of pores and grains in the compact is uniform and that the strain rate, $\dot{\varepsilon}$, for the fully densified material under a uniaxial stress, $\sigma$, is given by a power law

$$
\dot{\varepsilon}=A \sigma^{n} \text {. }
$$

They have constructed densification models for the initial stage of sintering, where discrete grains are connected by well-defined necks, the interinediate stage of sintering, for which pores are cylindrical and isolated, and the final stage of sintering, characterized by isolated, spherical pores.

We have taken $n=3$ in Equation (9) and calculated densification rates for the initial stage and the intermediate stage, the models most likely to describe the densification process over the depth interval we are considering. We have considered the case where the applied load is the overburden and have also let the applied load be the effective neck stress. We find that for either case, Wilkinson and Ashby's creep-controlled densification models predict that coarse firn densifies more rapidly than fine firn, as observed. However, for flow-law exponents greater than one, predicted densification rates for either fine or coarse firn increase with depth, making these models unacceptable. However, if a Newtonian viscous creep mechanis n were operating at the temperatures $\left(\sim-54.0^{\circ} \mathrm{C}\right)$ and applied neck stresses ( 1 bar) occurring here, then the Wilkinson and Ashby creep models would be viable candidates for the dominant densification mechanism.

However, it is difficult to assess the relative nagnitude of the different densification models discussed above due to uncertainties in the values of the relevant paraneters that appear in the tineories. such as the exponent $n$ and the factor $A$ in the flow law. We tentatively conclude that diffusion mechanisins do not dominate the densification process for 
both fine and coarse firn in the near-surface region at Dome $C$, while the status of a power-law, mechanical-creep mechanism as the dominant process in the densification of fine or coarse firn is more uncertain. We may expect particle rearrangement to play a significant role in the densification of coarse firn, while for fine firn the more stable structure may restrict the dominant densification mechanisms to diffusion and evaporation-condensation.

Currently no unified theory exists which explains a11 of the observed phenomena of densification and recrystallization in polar firn. More empirical data are needed to define trends in crystal-size and shape parameters and crystal-bond characteristics. Theoretical work is also needed, especially to quantify the contribution of grain boundary slip to the densification process, before such a unified theory can begin to emerge.

\section{ACKNOWLEDGEMENTS}

This work was supported by US National Science Foundation grant DPP-76-23428. Special thanks are due to Ron Coffinan for technical assistance during the core analysis and to Robert Tope for drafting the diagrams.

\section{REFERENCFS}

Alley R B 1980 Densification and recrystallization of firn at Dome $C$, central East Antarctica. Ohio State University. Institute of Polar Studies. Report 77

Budworth D W 1970 An introduction to ceramic science. 0xford, Pergamon Press

Coble R L 1970 Diffusion models for hot pressing with surface energy and pressure effects as driving forces. Joumal of Applied Physics 41(12): 4798-4807

Fullman R L 1953 Measurement of particle sizes in opaque bodies. Transactions of the Metallurgical Society of the A.I.M.E. 212: 452-455

Gow A J 1969 on the rates of growth of grains and crystals in South Polar firn. Joumal of Glaciology 3(53): 241-252

Gow A J 1975 Time-temperature dependence of sintering in perennial isothermal snowpacks. Interm national Association of Hydrological Soiences Publication 114 (Symposium of arindelwald 1974 Snow Mechanics) : 25-41

Kry $P R \quad 1975$ Quantitative stereological analysis of grain bonds in snow. Joumal of Glaciology 14(72): $467-477$

Palais J M 1980 Snow stratigraphic investigations at Tome $C$, East Antarctica: a study of depositional and diagenetic processes. Ohio state University. Institute of Poiar Studies. Report 78

Raynaud D, Duval P, Lebel B, Lorius C 1979 Crystal size and total gas content of ice: two indicators of the climatic evolution of polar ice sheets. Colloque international. Evolution des atmospheres planetaires et climatologie de la terre... Nice ... 1978. Toulouse, Centre ivational d'Etudes Spatiales: $33-94$

Smith C S, Guttinan L 1953 Measurenent of internal boundaries in three-dimensional structures by randon sectioning. Joumal of Metals 5(1): $81-87$

Stephenson P J 1967 Some considerations of snow metamorphism in the Antarctic ice sheet in the light of ire crystal studies. In oura $H$ (ed) 7hyeices of snow and icc: Intermational conference ori luw temrerature science...1966...Proceedings 1(2). Sapporo, Hokkaido University. Institute of Low Temperature Science: $725-740$
Wilkinson D S, Ashby M F 1975[a] The development of pressure sintering maps. In Kuczynski $G \mathrm{C}$ (ed) Sintering and catalysis: Proceedings of the fourth Intermational Conference on Sintering and Related Phenomena ... Notre Dame, Indiana ... 1975. New York and London, Plenum Press: 473-492 (Materials Science Research 10)

Wilkinson D S, Ashby M F 1975[b] Pressure sintering by power law creep. Acta Metallurgica 23: 1277-1285 